\title{
Prevalence of hypodontia in Chinese orthodontic patients
}

\author{
Pambudi Rahardjo \\ Department of Orthodontics \\ Faculty of Dentistry Airlangga University \\ Surabaya - Indonesia
}

\begin{abstract}
Hypodontia is a phenomenon of congenitally missing teeth in human. A thousand and twelve panoramic radiographs of Chinese orthodontic patients were examined for agenesis of permanent teeth including third molars. The patients with missing teeth were divided into four group: the patients with missing less than 4 molars, missing all third molars, hypodontia and oligodontia. The result revealed, 210 patients affected one or more teeth agenesis with a total of 455 teeth missing. The prevalence of tooth agenesis was maxillary third molar 259 (56.9\%), mandibular third molar 143 (31.4\%), mandibular second premolar 15 (3.3\%), mandibular lateral incisors $13(2.8 \%)$, maxillary lateral incisors $8(1.7 \%)$, maxillary second premolars $7(1.5 \%)$, other teeth $10(2.2 \%)$ respectively. Of the mesial mandibular first permanent molar, mandibular second premolars were the most frequent missing teeth. Although hypodontia did not represent a public health problem, from orthodontic point of view it might cause esthetic and masticatory function disorders as well as more complex mechanotherapy of a patient.
\end{abstract}

Key words: hypodontia, Chinese, mandibular second premolar

Correspondence: Pambudi Rahardjo, c/o: Bagian Ortodonsia, Fakultas Kedokteran Gigi Universitas Airlangga. Jln. Mayjend. Prof. Dr. Moestopo 47 Surabaya 60132, Indonesia.

\section{INTRODUCTION}

Some people born, having problem with unable to develop a full set of teeth, due to disturbance occurred during the development of the tooth. This condition commonly called hypodontia, a congenitally absence of one or a few deciduous or permanent teeth. Hypodontia could occur as an isolated sporadic or a familial trait. The most common permanent teeth missing are the third molars $(20 \%)$, second premolars $(3.4 \%)$ and maxillary lateral incisors $(2.2 \%){ }^{1}$

Some authors excluded the third molars in their studies. $^{2-8}$ An investigation in two countries in Norway reported that the most often missing teeth were mandibular second premolars (47\% of all missing teeth) followed by maxillary second premolars and lateral incisors (both $20 \%$ of all missing teeth). The prevalence was higher in females $(5.1 \%)$ than in males $(4.0 \%){ }^{2}$ Steffen et al. ${ }^{3}$ after examined 968 panoramic radiographs of orthodontic patients (463 females, 505 males) reported that hypodontia of at least one missing tooth was recorded in 89 patients. One hundred and thirty one tooth buds were missing. The most frequent effected tooth was the lower second premolars $(52 \%)$, second upper premolar $(27 \%)$ and upper lateral incisors (21\%) respectively.

An examination of 739 healthy Caucasian 7 year-olds proved the prevalence of hypodontia excluding third molars in girls was $8.4 \%$, in boys $6.5 \%$ and in both sexes combined $7.4 \%$. Of the children with hypodontia, the majority $(90.9 \%)$ lacked one or two teeth. Lower second premolar were the teeth most frequently missing. ${ }^{4}$ Another study of
111 orthodontic patients (46 males and 65 females) revealed the fact that agenesis was found in $8.1 \%$ of the patients ( 2 males and 7 females) and the mandibular second premolars was the most commonly affected teeth, excluding the third molars. ${ }^{5}$

A survey in Korea which performed on 721 school children found the most common congenitally missing teeth were mandibular second premolars $(32.7 \%)$ followed by the mandibular incisors $(28.7 \%)$, the second maxillary premolars $(16.7 \%)$ and the maxillary lateral incisors $(10.2 \%)$. The prevalence of congenitally missing teeth was $6.7 \%$ in boys and $9.5 \%$ in girls and $8.0 \%$ for both sexes combined. ${ }^{6}$

A study conducted in Hong Kong to determine the prevalence of hypodontia and hyperdontia of permanent teeth amongst Southern Chinese children. The results was as follows: the prevalence of congenitally missing teeth (third molar excluded) $6.1 \%$ in boys and $7.7 \%$ in girls and $6.9 \%$ for both sexes combined; the most commonly absent tooth was the mandibular incisors, affecting $58.7 \%$ of the children with hypodontia. ${ }^{7}$

An investigation was performed to examine the effects of advanced hypodontia on craniofacial morphology in Japanese patients. The most frequently missing teeth were the mandibular and maxillary second premolar, followed by the maxillary first premolars and the maxillary first molar, in that order. 8

The aim of this survey was to examine the prevalence of hypodontia including third molars in Chinese orthodontic patients treated in private orthodontic practice and ranked the missing teeth according to the prevalence. 


\section{MATERIAL AND METHODS}

The pre-treatment panoramic radiographs of 1012 Chinese orthodontic patients ( 734 females and 278 males) treated at private practice were evaluated retrospectively for agenesis of permanent teeth including third molars. The patients age range from 8 to 38 years. None of the patients has undergone extraction of permanent teeth and orthodontic treatment as well.

The patients with missing teeth were grouped into 4: the patients with missing less than 4 molars, the patients with missing all third molars, the patients with hypodontia (missing 1 to 6 teeth) and patients with oligodontia (missing more than 6 teeth). The data was analyzed descriptively and the prevalence of missing teeth was then ranked.

\section{RESULTS}

The distribution of the patients according to age, the number of patients with agenesis and the number of teeth missing can be seen in table 1-3.

Table 1. The distribution of the patients according to age

\begin{tabular}{cc}
\hline Age & Number \\
\hline$<10$ & $8(0.7 \%$ \\
$10-19$ & $832(82.2 \%)$ \\
$20-29$ & $160(15.8 \%)$ \\
$\geq 30$ & $12(1.1 \%)$ \\
\hline Total & 1012 \\
\hline
\end{tabular}

Table 2. The number of patients with agenesis

\begin{tabular}{lc}
\hline \multicolumn{1}{c}{ Toothagenesis } & Number \\
\hline$<4$ third molars & $146(14.4 \%)$ \\
4 third molars & $39(3.8 \%)$ \\
Hypodontia & $24(2.37 \%)$ \\
Oligodontia & $1(0.09 \%)$ \\
\hline \multicolumn{1}{c}{ Total } & $210(20.7 \%)$ \\
\hline
\end{tabular}

Table 3. The number of teeth missing

\begin{tabular}{lc}
\hline \multicolumn{1}{c}{ The tooth missing } & Number \\
\hline Max. $3^{\text {nd }}$ molar & $259(56.9 \%)$ \\
Mand. $3^{\text {nd }}$ molar & $143(31.4 \%)$ \\
Mand. $2^{\text {nd }}$ premolar & $15(3.3 \%)$ \\
Mand. $2^{\text {nd }}$ inci sors & $13(2.8 \%)$ \\
Max. $2^{\text {nd }}$ inci sors & $8(1.7 \%)$ \\
Max. $2^{\text {nd }}$ premolars & $7(1.5 \%)$ \\
Other teeth & $10(2.2 \%)$ \\
\hline \multicolumn{1}{c}{ Total } & 455 \\
\hline
\end{tabular}

The patients under 10 years of age and over 30 years were almost the same in number. The patients between 10 to 19 years of age was $832(82.2 \%)$ and the patients between 20 to 29 years of age was $160(15.8 \%)$.

The total number of teeth missing was 455 and upper third molars was the most missing teeth $(56,9 \%)$. The third mandibular molars was in the second rank, followed by mandibular second premolars.

\section{DISCUSSION}

All permanent tooth crowns except the third molars have begun their mineralization by age of six. Usually at the age of 8 to 10 years the first sign of the third molar appeared on the radiograph, but occasionally on older age. The formation of dentition continues many years and differences exist in mineralization depending on race, gender, family and individual. Therefore, diagnosis of tooth agenesis in permanent dentition should be made after the age of 6 (excluding third molars), and by 10 years of age if third molars were also studied. ${ }^{9}$ The youngest patient in this study was 8 years of age, and the number of the patients under 10 years were only $8(0.7 \%)$. The distribution of patients by age was dominated by patients whose age between 10 to 19 years and followed by patients of 20 to 29 years of age. All the patients were suitable as sample in this study according to age. In general, the patients in group of 10 to 19 years was the most having benefit of orthodontic treatment.

In this survey the third molar was included even though some authors ${ }^{2-8}$ excluded third molar in their investigation. The reason for including third molar in this study was the presence of third molar was still in controversy as an etiologic factor of mandibular anterior crowding in later age. As a tendency of human evolution it was believed that most of the people would not have third molar in their dentition. The total number of patients with missing third molars, in a variation from 1 to 4 , was $185(18.2 \%)$, smaller than what was reported by da Silva. ${ }^{1}$ Unfortunately, most of the study did not include third molars, especially the study with the sample of Mongoloid race, ${ }^{6-8}$ so it was difficult to compare the prevalence of missing molars. The prevalence of patients who has four molars was still much higher than those who did not. It means that the patients who will have the probability of facing sequelae of the third molars were still high. Thirty nine (3.8\%) patients missed all four molars, a very small portion of patients who would not suffer from negative effects from the presence of third molars.

The prevalence of patients with hypodontia was 24 $(2.37 \%)$ and oligodontia was found in only 1 patient $(0.09 \%)$. This patient with oligodontia missed 14 teeth (including third molars) in symmetrical order (right and left side). He lost both the maxillary third molars, second molars, second premolars, canines and mandibular third molars, second premolars and lateral incisors.

The number of teeth missing was 455 and the most 
frequent teeth missing were maxillary third molars (259 teeth), followed by mandibular third molars (143). Fifteen mandibular second premolars were missing (3.3\%), mandibular lateral incisors $13(2.8 \%)$, maxillary lateral incisors $8(1.7 \%)$ and maxillary second premolars $7(1.5 \%)$. Of the mesial first permanent teeth, mandibular second premolars were the most frequent missing teeth and this finding was in accordance with other studies. ${ }^{1-6,8}$

The term hypodontia was most frequently used when describing the phenomenon of congenitally missing teeth in general. Many other terms appeared in literature to describe a reduction in number of teeth: oligodontia, anodontia, aplasia of teeth, congenitally missing teeth, absence of teeth, agenesis of teeth and lack of teeth. But two of this terms (oligodontia and anodontia) had a specific meaning; oligodontia was defined as missing a large number of teeth (more than 6 teeth), while anodontia was an extreme condition denoting complete absence of teeth. An author proposed a term advance hypodontia, for agenesis more than 4 teeth excluding third molars. ${ }^{8}$ Even though hypodontia could occur in primary teeth but the term hypodontia was used for permanent dentition in this study. Hypodontia could be easily found by examining panoramic or periapical radiograph but panoramic was recommended. The advantage of using panoramic radiograph in assessing agenesis was the broad coverage of the area to be studied. A horizontally maxillary canine located high in palatal vault was invisible in the periapical radiograph, and might be misinterpreted as agenesis of maxillary canine.

Tooth agenesis in human can be understood as an evolutionary trend, and LEF1 is one of the molecules that played a leading role during the evolution of dentition patterning. ${ }^{1}$ The underlying causes of this phenomenon were mostly unknown. Mutation of the MSX1 and PAX9 gene were identified as the cause of selective tooth agenesis in human, and played a role in early tooth development. ${ }^{9-13}$ It affected both primary and permanent teeth, but predominantly involving premolars.

The hypodontia of mandibular lateral incisors was the second most frequently found in this survey. In case of hypodontia it was some times difficult to clinically differentiate mandibular lateral incisors and the central which was missing. But it was believed and proved in many studies that mandibular lateral incisors was more frequently missing than the central. As a general rule, if only one or a few teeth were missing, the absence of tooth would be the most distal tooth of any given type. If a molar tooth was congenitally missing, it was almost always the third molar; if an incisor was missing, it was nearly always the lateral; if a premolar was missing, it almost always the second rather than the first. ${ }^{14}$

The occurrence of missing second premolars can cause difficulty in treatment planning of orthodontic problem. If extraction of first premolar was indicated in the treatment plan but the second premolar was congenitally missing there would be difficulty in carrying the treatment on, because the operator should retract more teeth to correct anterior crowding. Extracting second premolar would have a risk of loosing of anchorage. The extraction of more distal teeth might alter the treatment planning and modified the mechanotherapy as well. The amount of space available to correct crowding was greater when a first premolar was extracted. If a more distal tooth was selected for extraction, space would inevitably be lost if molars slipped forward rather than canine or premolars moving distally. In this case, a maximum anchorage was needed to prevent anchorage loss and it means a longer treatment time due to preparing the good anchorage before correcting anterior malalignment.

Another clinical association of missing premolars was infraocclusion of deciduous first molars due to ankylosis. ${ }^{15-17}$ The exact mechanism for initiation of ankylosis was not known. Infraoccluded deciduous molars were believed to remain static while the adjacent teeth move vertically with growth and development of the alveolar process. This left the deciduous molar teeth in a progressively inferior position in relation to the occlusal plane, giving the visual impression that it was submerging. A restorative crown some times needed for this case.

The conclusion of this survey is the rank of hypodontia in Chinese orthodontic patients is as follows: maxillary third molars, mandibular third molars, mandibular second premolars, mandibular lateral incisors, maxillary lateral incisors and maxillary second premolars. Although hypodontia did not represent a public health problem, from orthodontic point of view it might cause esthetic and masticatory function disorders as well as more complex mechanotherapy of a patient.

\section{ACKNOWLEDGEMENTS}

The author was very much obliged to late Prof. Dr. Soekotjo Djokosalamoen, MSc. drg. Sp. Ort. whose permission to examine his orthodontic patients' records made possible this survey.

\section{REFERENCES}

1. da Silva ER, Peres RCR, Scarel-Caminaga RM, DeConto F, Line SRP. Absence of mutation in the promoter region of the LEF1 gene in patients with hypodontia. Braz J Oral Sci. 2003; 2(4):144-6.

2. Nordgarden H, Jensen JL, Storhaug K. Reported prevalence of congenitally missing teeth in two Norwegian countries. Comm Dent Health 2002; 19:258-61.

3. Steffen W, Rohling J, Bauss O. Prevalence of symptoms of disturbed development of the dentition. J Dent Oral Med 2006; 8(1): 307.

4. Backman B, Wahlin YB. Variation in number and morphology of permanent teeth in 7-year-old Swedish children. Int J Pediatric Dent 2000; 10:11-7.

5. Thongudomporn U, Freer TJ. Prevalence of dental anomalies in orthodontic patients. Aust Dent J 1998; 43(6):395-8.

6. Lee T, Moon H. Genetic linkage analysis for the pedigree data of hypodontia of permanent teeth. Available at: www.isi.cbs.nl/ iamamember/CDI/abtracts/papers/2182pdf. Accessed October 26, 2006.

7. Davis PJ. Hypodontia and hyperdontia of permanent teeth in Hong Kong schoolchildren. Com Dent Oral Epidemiol 1987; 15:218-21.

8. Endo T, Ozoe R, Yoshino S, Shimooka S. Hypodontia pattern and 
variation in craniofacial morphology in Japanese orthodontic patients. Angle Orthod 2006; 76(6): 996-1003.

9. Arte S. Phenotypic and genotypic features of familial hypodontia. Academic dissertation, Helsinky University 2001. Available at: www. ethesis,helsinky.fi/julkaisut/laa/hamma/vk/arte. Accessed October 27, 2006.

10. Klein ML, Nieminen P, Lammi L, Niebuhr E, Kreiborg S. Novel mutation of the initiation of PAX9 causes oligodontia. J Dent Res 2005; 84(1):43-7.

11. Frazier-Bowers SA, Pham KY, Le EV, Cavender AC, Kapadia H, King TM, et al. A unique form of hypodontia seen in Vietnamese patients: clinical and molecular analysis. J Med Genet 2003; 40: 79-82.

12. Vastardis H, Karimbou N, Guthua SW, Seidman JG, Seidman CE. A human MSX1 homeodomain missence mutation causes selective tooth agenesis. Nat Genet 1996; 13:417-21.
13. Graber TM, Vanarsdall Jr. RL, Vig KWL. Orthodontics, current principles and techniques. $4^{\text {th }}$ ed. St Louis Missouri, Toronto: Mosby, an imprint of Elsevier; 2005. p. 109.

14. Proffit WR, Field Jr HW. Contemporary orthodontics. $3^{\text {rd }}$ ed. Mosby, an imprint of Elsevier; 2000. p. 118, 228-9.

15. Kurol J, Thilander B. Infraocclusion of primary molars with aplasia of the permanent successor, a longitudinal study. Angle Orthod 1984; 54:285-94.

16. Sidhu HK, Ali A. Hypodontia, ankylosis and infraocclusion: report of a case restored with a fibre-reinforced ceromeric bridge. Br Dent J 2001; 191(11):613-6.

17. Kokich VG, Kokich VO. Congenitally missing mandibular second premolars: clinical options. Am J Orthod Dentofac Orthop 2006; 130(4): 437-44. 